Neurosurg Focus 13 (2):Article 3, 2002, Click here to return to Table of Contents

\title{
Lumbar microdiscectomy: a historical perspective and current technical considerations
}

\author{
Christopher J. Koebbe, M.D., Joseph C. Maroon, M.D., Adnan Abla, M.D., \\ Hikmat El-Kadi, M.D., AND JefFery Bost, P.A.C. \\ Department of Neurological Surgery, University of Pittsburgh Medical Center, Pittsburgh, \\ Pennsylvania
}

\begin{abstract}
A historical review is presented of the original descriptions of lumbar discectomy, focusing on the evolution toward a less invasive surgical approach following the introduction of the operating microscope. From the initial work in Europe by Yaşargil and Caspar to the popularization of microdiscectomy by Williams and Wilson in the United States, this procedure has successfully reduced operative time, surgical morbidity, and incision size while allowing patients to return to work faster. Emphasis is placed on the importance of a careful preoperative clinical and radiographic evaluation by identifying factors that may help in the prediction of a successful surgical outcome. A modification of the lumbar microdiscectomy technique is described including patient positioning in the lateral position as well as minimal disc space and nerve root manipulation. In their experience performing more than 3000 microdiscectomies, the authors have produced good-to-excellent clinical results in nearly $90 \%$ of patients, with the majority returning to work within 1 month. The complication rate of dural tears, discitis, or root injury has been less than $2 \%$, with a reoperation rate of $5 \%$. The authors believe that lumbar microdiscectomy remains the gold standard with which all other discectomy techniques must be compared.
\end{abstract}

KEY WORDS • lumbar spine • microdiscectomy • history

Lumbar discectomy has become the most common neurosurgical procedure in the US, with nearly 300,000 procedures performed each year because of the epidemic problem of low-back pain, which leads to 15 million physician visits per year and has created a tremendous financial burden on society exceeding $\$ 50$ billion annually. ${ }^{10,15,23,28}$ A retrospective analysis of Workers' Compensation claims at a large industrial manufacturer within the US found $19 \%$ of claims were related to back injuries, and these claims were responsible for a disproportionate $41 \%$ of total injury costs. ${ }^{61}$ Low-back pain causes nearly $80 \%$ of injured workers to miss at least 8 weeks of work following a back injury. ${ }^{44}$ In persons younger than 45 years old, low-back pain is the most frequent cause of activity limitation. ${ }^{39}$ Although only $2 \%$ of patients with low-back pain have an acute disc herniation, a disproportionate $30 \%$ of US annual costs for the treatment of low-back pain are spent on this relatively small percentage of patients. ${ }^{57} \mathrm{We}$ review of the history of lumbar disc disease with a focus on the evolution of surgical treatment leading toward microdiscectomy and then present lessons learned from more than 2500 lumbar microdiscectomies performed by the senior author.

Abbreviations used in this paper: $\mathrm{CT}=$ computerized tomography; HLD = herniated lumbar disc; $\mathrm{LDH}=$ lumbar disc herniation; MR = magnetic resonance; US = United States.

\section{HISTORICAL PERSPECTIVE}

The operative treatment of lumbar disc disease has challenged spine surgeons since the first reported case in 1929 by Dandy. ${ }^{14}$ In 1934, William J. Mixter, a neurosurgeon at Harvard College, and his orthopedic colleague, Joseph Barr, first elucidated the pathophysiology of the age-old curse often described as lumbago or sciatica. ${ }^{46}$ They reviewed and synthesized the case reports by Oppenheim, Goldthwait, Ellsberg, Bucy, Dandy, Petit-Dutallis, Schmorl, and others, added 11 cases of their own, thus providing the information substrate and the catalyst that would lead to the preoperative diagnosis and the surgical cure of millions of people with intractable pain. Far from minimally invasive, the lumbar discectomy technique described by Mixter and Barr involved an extensive removal of the lamina and offending ruptured disc through an intradural approach. ${ }^{24,46}$ Their technique was used during much of the Cold War era and underwent only subtle alteration until a less invasive microsurgical dissection was introduced in the late 1960s, which resulted in shortened hospital stays, less surgical morbidity, and a faster return to work for the patient. ${ }^{25,31,34,65,67,69,70}$ The first publications documenting the microsurgical discectomy procedure were in 1977: both Yaşargil ${ }^{74}$ working in Switzerland and Caspar ${ }^{11}$ working in Germany reported their experience in applying the operating microscope to surgery for lumbar disc disease. During the following year, Wil- 
liams ${ }^{70}$ whose referral base included Las Vegas showgirls, popularized the microdiscectomy technique in the US. He demonstrated in a series of 532 patients that surgical scars could be minimized and patients could return to work more quickly through the use of a more conservative technique of removing only a portion of the offending disc to decompress the affected nerve root. A debate ensued over which microsurgical technique produced the best outcome while preventing recurrences and the need for reoperation: Caspar and colleagues, ${ }^{12}$ Wilson and Harbaugh ${ }^{71}$ and others believed a more extensive removal of the disc was needed to prevent recurrence and provide better relief of the nerve root compression. Despite this debate, Goald, ${ }^{25}$ Wilson and Harbaugh, ${ }^{71}$ Maroon and Abla ${ }^{43}$ and many others ${ }^{12,53,58,69}$ have confirmed the ability to reduce incision size, blood loss, and morbidity with the microsurgical technique compared with other discectomy techniques. Success rates in microdiscectomy range from 88 to $98.5 \%$ in various series, although authors of a recent study suggest that a success rate of 75 to $80 \%$ is a more accurate and realistic outcome expectation. 3,5,18,31,43,58,71,72

Almost all significant technical advances are initially met with skepticism if not active resistance. This was certainly the case with the operating microscope and, in particularly, with its application to microsurgery of the lumbar disc. The small incision, diminished muscle trauma, and manipulation of neural structures allowed by a magnified view into the disc space under coaxial illumination has softened this resistance, and the majority of neurosurgeons now use the operating microscope to perform lumbar disc surgery. Over the past decade, lumbar microdiscectomy has become an outpatient procedure with success rates equal to those found in initial microdiscectomy studies. $^{40}$

\section{PREOPERATIVE ASSESSMENT}

Before focusing on the intraoperative approach to microdiscectomy a brief discussion of preoperative evaluation is warranted. The incidence of LDH peaks in patients between 24 and 45 years of age with the incidence leading to surgery occurring most often in patients in the 30- to 39 -year-old range. ${ }^{60} \mathrm{~A}$ male predominance in the incidence of lumbar disc surgery ranges from 1.3:1 to 2:1 because discs in men undergo higher mechanical stress as well as inadequate nutrition due to longer nutrient diffusion pathways. ${ }^{13,47}$ Other risk factors for HLD include smoking, presence of narrower lumbar vertebral canal, sedentary occupations, prolonged motor vehicle driving, and operating vibrating machinery. ${ }^{10,29,35-38,45,52,67,73}$ Most surgeons initially manage patients with low-back pain and radicular symptoms with a trial of analgesic medications and physical therapy for several weeks before pursuing the option of costly radiographic studies and discussing surgical intervention because 90 to $95 \%$ of patients recover without surgery. ${ }^{20}$

A careful preoperative history taking and physical examination are crucial in selecting appropriate surgical candidates. The duration of radicular symptoms as well as the presence of crossed Lasègue sign are important in the selection criteria, because patients with radiculopathy and sustained back pain for 6 months or more have more severe disc disease and poorer outcomes. ${ }^{32,41,48,64-66}$ Other clinical predictors of good outcome from surgery include: no preoperative comorbid conditions, no previous nonspinal surgery, the absence of a Workers' compensation claim, younger age, presence of radicular distribution pain extending to the foot, positive straight-leg rising examination without back pain, and reflex asymmetry; each of these factors independently predicted a good outcome from lumbar discectomy. ${ }^{1,5,16,42}$ Cerebrospinal fluid markers such as neurofilament and S100 proteins may provide additional data if needed to substantiate evidence of axonal and Schwann cell damage due to LDH compressing the nerve root. ${ }^{9}$

For a patient with persistent radiculopathy suggestive of $\mathrm{LDH}$, neuroimaging evaluation is necessary to determine if nerve root compression by a herniated disc corresponds to the clinical condition. Magnetic resonance imaging has replaced CT and myelography as the initial test of choice for several reasons (Fig. 1). Magnetic resonance imaging is less invasive, obviating the need for lumbar contrast injection. Magnetic resonance imaging appears to correlate more accurately with surgical findings at a rate of $90 \%$ compared with $77 \%$ for CT imaging, ${ }^{21}$ and MR imaging is more sensitive (100\%) than discography (86\%) in detecting HLD. ${ }^{7}$ If MR studies fail to provide clear evidence of LDH at the level corresponding with the clinical presentation, myelography is a useful adjuvant study particularly when no neurological deficit exists, multiple nerve roots are involved, or when a centrally herniated disc affects only a single root. Regardless of which neuroimaging study is chosen, the findings on the neuroimaging study must be supported by clinical evidence of nerve root compression as false-positive studies are not uncommon. ${ }^{8}$ Wiesel, et al. ${ }^{68}$ studied neuroradiologists' readings of lumbar CT scans obtained in 52 volunteers with no back or leg pain and found radiographic abnormalities in $37 \%$ of these "normal" individuals, particularly in those older than 40 years of age. Jensen, et al., ${ }^{33}$ performed MR imaging examinations in 98 people without back pain and found $52 \%$ had a disc bulge at one level, $27 \%$ had a protrusion, and one patient had an extruded disc. For those patients with persistent pain and radicular symptoms as well as neuroimaging evidence of disc herniation, surgery has been shown to be beneficial. A prospective study of 283 patients with clinical and myelographic evidence of LDH and 126 patients with uncertain indications who

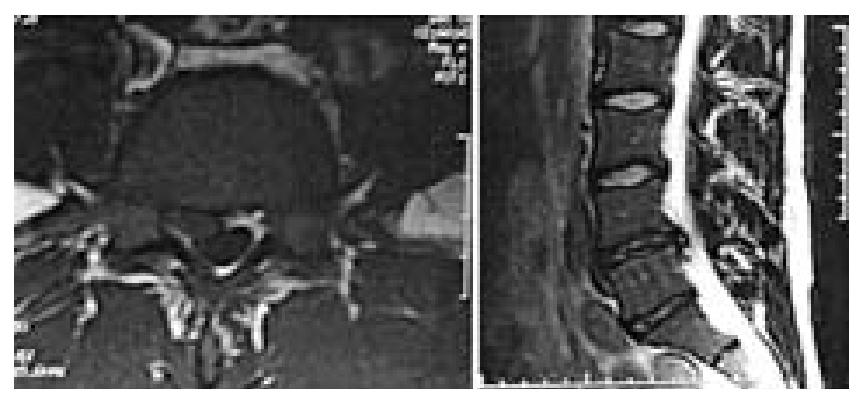

Fig. 1. Axial (left)and sagittal (right) $\mathrm{T}_{2}$-weighted MR images of an L4-5 paramedian herniation of the nucleus pulposus through a ruptured anulus fibrosis. 
were randomized into a continued conservative therapy group and a surgically managed group showed short-term success with $90 \%$ satisfaction in the surgically managed group compared with $66 \%$ satisfaction in the conservative therapy group at 1 year; however, this difference lost statistical significance at 4 years with $80 \%$ compared with $68 \%$ patient satisfaction, respectively. ${ }^{67}$ Shvartzman, et al. ${ }^{57}$ reviewed the cases of 55 male truck drivers following 3 months of conservative therapy to treat acute HLD. They found no significant difference in outcome or costs between continuing conservative therapy compared with surgery; however, the conservatively treated group did miss 18.5 more weeks of work over a 5-year period than those who underwent surgery. The anatomical continuity of the anulus fibrosis following disc herniation helps to predict surgical success because patients with an extruded disc fragment through the ruptured anulus on surgical examination have better clinical outcomes at 2 years compared with patients with contained herniation or disc disease. ${ }^{64}$ There is a clear advantage to surgical treatment when patients are seeking immediate relief of pain and a faster return-to-work time.

\section{SURGICAL TECHNIQUE}

The surgical approach is similar, with a few modifications, to that described by Yaşargil, ${ }^{74}$ Caspar, ${ }^{11}$ and Williams. ${ }^{69,70}$ Patients are placed in a slightly flexed lateral decubitus position, with the affected side up and the surgeon seated (Fig. 2 upper). Fluoroscopic or radiographic confirmation of the correct interspace is obtained with a radiopaque skin marker. Prophylactic intravenously administered antibiotics are given in one dose at least 30 minutes prior to the skin incision. A $15-$ to $25-\mathrm{mm}$ skin incision is made just lateral to the appropriate spinous processes; the lumbodorsal fascia is incised $2 \mathrm{~mm}$ from its insertion and a subperiosteal dissection exposes the inferior third of the lamina above the ligamentum flavum, the medial facet, and the upper portion of the inferior lamina. A Williams retractor, either 1 or $2 \mathrm{~cm}$ wide and 5 to $7 \mathrm{~cm}$ long, maintains the exposure. At this point, a second radiograph may be obtained.

The operating microscope with a $300-\mathrm{mm}$ objective is then brought into use. A low-profile, angled, high-speed drill with a 4- to 5-mm coarse diamond bit is used to thin the inferior lamina, medial facet, and superior lamina surrounding the interspace. A small curette is used to detach the ligamentum flavum directly over the nerve root inferolaterally and a 2-mm angled Kerrison rongeurs is used to begin the simultaneous bone removal over the nerve root and then laterally and superiorly to detach the ligamentum flavum and obtain a minimal medial facetectomy and achieve removal of the thinned inferior bone of the superior lamina. One-, two- and three-millimeter rongeurs are used to remove the ligamentum flavum as needed but the medial portion is usually preserved so that it still overlies the nerve root.

The remainder of the operation is performed in the standard fashion. Epidural veins are coagulated with low-setting bipolar forceps. The disc is palpated with a blunt Penfield dissector or right angle nerve hook, and the nerve root is retracted using a blunt suction tip. Free fragments are removed from the epidural space, and the posterior longitudinal ligament is incised and nuclear material is removed in the standard fashion (Fig 2 lower left). After thorough superior, medial, and inferior exploration, a foraminotomy is completed; the fascia is closed with two to three sutures and the skin is closed with a subcutaneous stitch. Steri strips and an adhesive bandage are applied to the wound (Fig 2 lower right).

Patients are urged to begin ambulating immediately and are discharged within 23 hours, either the same day or the following morning, in $95 \%$ of the cases. Most patients have returned to work within 1 month after microsurgery for an extruded fragment; these results have not changed significantly since our earlier report. ${ }^{43}$ The mean operating time is usually 30 to 60 minutes. Approximately $90 \%$ of patients obtain good-to-excellent pain relief.

\section{MANAGEMENT OF COMPLICATIONS AND RECURRENCES}

The incidence of complications in our series involving more than 2500 procedures such as dural tears, nerve root injury, and discitis is less than $1.5 \%$. Cerebrospinal fluid leak and subsequent pseudomeningocele can be prevented by immediate recognition of a dural tear and primary repair with application of tissue glue or a dural substitute as needed. One of the least common yet extremely painful complications of lumbar disc surgery is discitis, which can be divided into two types. ${ }^{22}$ Septic discitis can be distinguished by the presence of fever, leukocytosis, positive bacteriological cultures, or histological features on biopsy

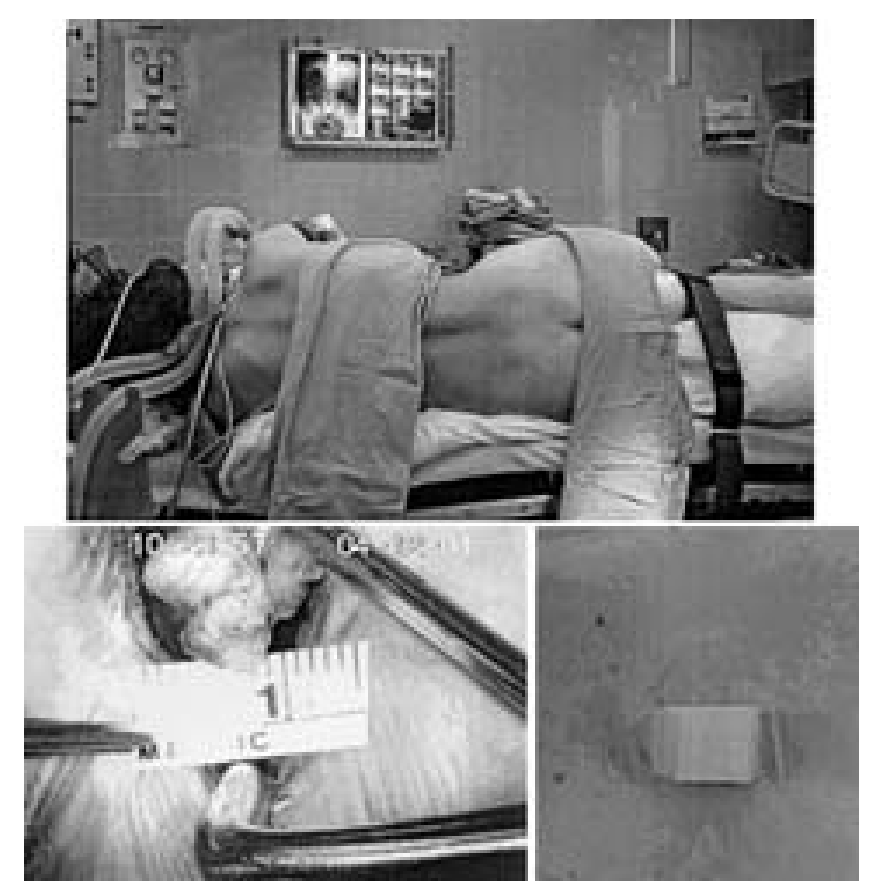

Fig. 2. Upper: The patient is positioned in the lateral decubitus position with the symptomatic side facing upward. Lower Left: Photograph showing the 15 - to $25-\mathrm{mm}$ incision during removal of the offending free disc fragment. Lower Right: Photograph of bandage placement after skin closure. 
as well as by an increase in erythrocyte sedimentation and $\mathrm{C}$-reactive protein. Sterile or asceptic discitis is thought to be due to chemical irritation and inflammation of the cartilaginous endplates of the vertebrae and does not result in wound infection, fever, or positive cultures and laboratory results. Wilson and Harbaugh ${ }^{71}$ reported that this occurred in $2.3 \%$ of cases and blamed it on the rongeurs flaking off pieces of cartilage during radical disc removal. The two entities need to be distinguished because septic discitis requires antibiotic therapy whereas aseptic discitis can be treated with rest and physical therapy. Case reports of great vessel or retroperitoneal injuries exist, and immediate laparotomy with fluid and blood replacement is required if this occurs. ${ }^{2,55,56} \mathrm{We}$ have not encountered such a complication and no death has occurred in more than 2500 operations.

Whether to remove just the extruded fragment, as advocated by Williams, ${ }^{70}$ or to remove more aggressively the nuclear material of the disc has been a heated point of discussion among those using the microsurgical approach; our reoperation rate was $5 \%$ in this series. The conservative surgical approach avocated by Williams, in which only the protruding disc fragment is removed rather than performing the more extensive discectomy initially, produced a recurrence rate of $9 \%$, whereas he reported a recurrence rate of only $5.5 \%$ in his later series ${ }^{69,70} \mathrm{He}$ concluded that the spontaneous reherniation rate was only $1.9 \%$, because two thirds of the total reherniations were due to new lumbar trauma. ${ }^{69}$ The work of Wilson and Harbaugh $^{71}$ who used a more aggressive discectomy to remove the entire disc material in hopes of preventing reherniation produced only a slightly lower recurrence rate of $4 \%$. A drawback applying to this technique was an increased risk of postoperative discitis and back pain, possibly due to greater irritation of the vertebral endplates. ${ }^{6}$ Results pooled from nine different series show a 3.7\% recurrence rate in cases involving more extensive disc excision, compared with a $7 \%$ rate after limited disc removal. ${ }^{4}$ Striffeler, et al. ${ }^{62}$ provided conflicting evidence: their comparison of Williams' conservative microsurgical discectomy with the technique reported by Caspar revealed no significant difference between the two groups in reoperation rates due to recurrence. Their finding ${ }^{62}$ is substantiated by another retrospective review in which no increase was reported in reherniation or reoperation rates when disc fragment excision alone was compared with discectomy and endplate currettage. ${ }^{6}$ These results suggest a more extensive removal of disc material involving curettage of the vertebral endplates causes increased risk of anular penetration and subsequent abdominal structure injury as well as greater postoperative back pain while offering little advantage in preventing recurrence.

Dealing with reherniation or return of sciatica symptoms can be one of the most difficult tasks faced by those performing lumbar spine surgery. The incidence of repeated surgery for recurrence ranges from 1.7 to $8 \%{ }^{26,30,49,54 \text {, }}$ $59,63,71$ Reports vary greatly as to how successful repeated microdiscectomy can be as 44 to $100 \%$ of patients are able to return to work and 56 to $88 \%$ have relief of their sciatica. ${ }^{17,27,50,59}$ The time interval between the initial procedure and recurrence of symptoms is an important predictor of success in reoperative procedures because patients with sciatica that recurs at least 1 year after the first operation have better outcomes, with success rates comparable to those of primary microsurgical lumbar discectomy. ${ }^{27,51}$ The surgical findings during repeated surgery for recurrent sciatica are also important in predicting outcome; the presence of scar formation and lack of definitive reherniation results in less satisfactory outcomes ${ }^{19}$ Based on the previous discussion and our excellent results, we will only remove the free disc fragment if it is massive and the extruded disc material is the clear source of root compression. If the herniation is still contained or contiguous with the disc space, we routinely aggressively remove the nuclear material. To reduce perineural fibrosis we preserve, as much as possible, the epidural fat and ligamentum flavum over the nerve root.

\section{CONCLUSIONS}

Lumbar discectomy as the surgical treatment of the HLD has certainly evolved since the initial reports of this disease entity more than 70 years ago. We have not focused on outcome measurements as that will be discussed in another article in this issue; however, we continue to have good-to-excellent patient satisfaction and successful functional outcomes in approximately $90 \%$ of our nearly 3000 procedures. We could not have achieved this rate of success without careful preoperative evaluation correlating clinical symptoms and signs to neuroimaging abnormalities. The extent of disc removal must be based on a case-by-case decision regarding the intraoperative appearance of the LDH. When a large free disc fragment is compressing the nerve root, we believe removal of the offending fragment alone minimizes the risk of serious complications without compromising pain relief or increasing recurrence rates. With extensive personal experience performing thousands of microdiscectomies and after investigating and using almost all percutaneous and standard operative techniques, we believe that the microsurgical approach for lumbar discectomy remains the gold standard against which all other procedures must be compared.

\section{References}

1. Abramovitz JN, Neff SR: Lumbar disc surgery: results of the Prospective Lumbar Discectomy Study of the Joint Section on Disorders of the Spine and Peripheral Nerves of the American Association of Neurological Surgeons and the Congress of Neurological Surgeons. Neurosurgery 29:301-308, 1991

2. Anda S, Aakhus S, Skaanes KO, et al: Anterior perforations in lumbar discectomies. A report of four cases of vascular complications and a CT study of the prevertebral lumbar anatomy. Spine 16:54-60, 1991

3. Andrews DW, Lavyne MH: Retrospective analysis of microsurgical and standard lumbar discectomy. Spine 15:329-335, 1990

4. Apostolides PJ, Jacobowitz R, Sonntag VH: Lumbar discectomy microdiscectomy: "the gold standard." Clin Neurosurg 43: 228-238, 1996

5. Asch HL, Lewis PJ, Moreland DB, et al: Prospective multiple outcomes study of outpatient lumbar microdiscectomy: should 75 to $80 \%$ success rates be the norm? J Neurosurg 96 (Spine 1):34-44, 2002

6. Balderston RA, Gilyard GG, Jones AA, et al: The treatment of lumbar disc herniation: simple fragment excision versus disc space currettage. J Spinal Disord 4:22-25, 1991 
7. Birney TJ, White JJ Jr, Berens D, et al: Comparison of MRI and discography in the diagnosis of lumbar degenerative disc disease. J Spinal Disord 5:417-423, 1992

8. Boden SD, Davis DO, Dina TS, et al: Abnormal magnetic-resonance scans of the lumbar spine in asymptomatic subjects. A prospective investigation. J Bone Joint Surg Am 72:403-408, 1990

9. Brisby H, Olmarker K, Rosengren L, et al: Markers of nerve tissue injury in the cerebrospinal fluid in patients with lumbar disc herniation and sciatica. Spine 24:742-746, 1999

10. Bruske-Hohlfeld I, Merritt JL, Onofrio BM, et al: Incidence of lumbar disc surgery. A population-based study in Olmsted County, Minnesota, 1950-1979. Spine 15:31-35, 1990

11. Caspar W: A new surgical procedure for lumbar disc herniation causing less tissue damage through a microsurgical approach. Adv Neurosurg 4:74-80, 1977

12. Caspar W, Campbell B, Barbier DD, et al: The Caspar microsurgical discectomy and comparison with a conventional standard lumbar disc procedure. Neurosurgery 28:78-87, 1991

13. Damkot DK, Pope MH, Lord J, et al: The relationship between work history, work environment, and low-back pain in men. Spine 9:395-399, 1984

14. Dandy WE: Loose cartilage from intervertebral disk simulating tumor of the spinal cord. Arch Surg 19:660-672, 1929 (Reference unverified)

15. Dixon A: Progress and problems in back pain research. Rheum Rehabil 12:165-175, 1973

16. Dvorak J, Gauchat MH, Valach L: The outcome of surgery for lumbar disc herniation. I. A 4-17 years' follow-up with emphasis on somatic aspects. Spine 13:1418-1422, 1988

17. Ebeling U, Kalbarcyk H, Reulen HJ: Microsurgical reoperation following lumbar disc surgery. Timing, surgical findings, and outcome in 92 patients. J Neurosurg 70:397-404, 1989

18. Ebeling U, Reichenberg W, Reulen HJ: Results of microsurgical lumbar discectomy. Review of 485 patients. Acta Neurochir 81:45-52, 1986

19. Fandino J, Botana C, Viladrich A, et al: Reoperation after lumbar disc surgery: results in 130 cases. Acta Neurochir 122: 102-104, 1993

20. Fast A: Low back disorders: conservative management. Arch Phys Med Rehabil 69:880-891, 1988

21. Forristall RM, Marsh HO, Pay NT: Magnetic resonance imaging and contrast $\mathrm{CT}$ of the lumbar spine. Comparison of diagnostic methods and correlation with surgical findings. Spine 13:1049-1054, 1988

22. Fouquet B, Goupille P, Jattiot F, et al: Discitis after lumbar disc surgery. Features of "asceptic" and "septic" forms. Spine 17: 356-358, 1992

23. Frymoyer JW, Cats-Baril WL: An overview of the incidences and costs of low back pain. Orthop Clin North Am 22: 263-271, 1991

24. Frymoyer JW, Donaghy RM: The ruptured intervertebral disc. Follow-up report on the first case fifty years after recognition of the syndrome and its surgical significance. J Bone Joint Surg Am 67:1113-1116, 1985

25. Goald HJ: Microlumbar discectomy: follow up of 147 patients. Spine 3:183-185, 1978

26. Goffin J: Microdiscectomy for lumbar disc herniation. Clin Neurol Neurosurg 96:130-134, 1994

27. Haglund MM, Moore AJ, Marsh H, et al: Outcome after repeat lumbar microdiscectomy. Br J Neurosurg 9:487-495, 1995

28. Hart LG, Deyo RA, Cherkin DC: Physician office visits for low back pain. Frequency, clinical evaluation, and treatment patterns from a U.S. national survey. Spine 20:11-19, 1995

29. Heliovaara M, Vanharanta H, Korpi J, et al: Herniated lumbar disc syndrome and vertebral canals. Spine 11:433-435, 1986

30. Hirabayashi S, Kumano K, Ogawa Y, et al: Microdiscectomy and second operation for lumbar disc herniation. Spine 18: 2206-2211, 1993
31. Hudgins WR: The role of microdisectomy. Orthop Clin North Am 14:589-603, 1983

32. Hurme M, Alaranta $\mathrm{H}$ : Factors predicting the result of surgery for lumbar intervertebral disc herniation. Spine 12:933-938, 1987

33. Jensen MC, Brant-Zawadzki MN, Obuchowski N, et al: Magnetic resonance imaging of the lumbar spine in people without back pain. N Engl J Med 331:69-73, 1994

34. Kahanovitz N, Viola K, Muculloch J: Limited surgical discectomy and microdiscectomy. A clinical comparison. Spine 14: 79-81, 1989

35. Kelsey JL: An epidemiological study of the relationship between occupations and acute herniated lumbar intervertebral discs. Int J Epidemiol 4:197-205, 1975

36. Kelsey JL, Githens PB, O'Connor T, et al: Acute prolapsed lumbar intervertebral disc. An epidemiologic study with special reference to driving automobiles and cigarette smoking. Spine 9:608-613, 1984

37. Kelsey JL, Golden AL, Mundt DJ: Low back pain/prolapsed lumbar intervertebral disc. Rheum Dis Clin North Am 16: 699-716, 1990

38. Kelsey JL, Ostfeld AM: Demographic characteristics of persons with acute herniated lumbar intervertebral disc. J Chronic Dis 28:37-50, 1975

39. Kelsey JL, Pastides H, Bisbee GE Jr: Musculo-skeletal Disorders: Their Frequency of Occurrence and Their Impact on the Population of the United States. New York: Prodist, 1978

40. Koebbe CJ, Perez-Cruet M: Outpatient lumbar microdiscectomy, in Perez-Cruet M, Fessler RG (eds): Outpatient Spinal Surgery. St. Louis: Quality Medical Publishing, 2002, pp 133-157 (Reference unverified)

41. Kotilainen E, Valtonen S, Carlson CA: Microsurgical treatment of lumbar disc herniation: follow-up of 237 patients. Acta Neurochir 120:143-149, 1993

42. Lewis PJ, Weir BK, Broad RW, et al: Long-term prospective study of lumbosacral discectomy. J Neurosurg 67:49-53, 1987

43. Maroon JC, Abla AA: Microlumbar discectomy. Clin Neurosurg 33:407-417, 1986

44. Mayer TG, Gatchel RJ, Mayer H, et al: A prospective two-year study of functional restoration in industrial low back injury. An objective assessment procedure. JAMA 258:1763-1767, 1987

45. Miller JA, Schmatz C, Schultz AB: Lumbar disc degeneration: correlation with age, sex, and spine level in 600 autopsy specimens. Spine 13:173-178, 1988

46. Mixter WJ, Barr JS: Rupture of the intervertebral disc with involvement of the spinal canal. N Engl J Med 211:210-215, 1934

47. Nachemson A, Lewin T, Maroudas A, et al: In vitro diffusion of dye through the end-plates and annulus fibrosus of human lumbar inter-vertebral discs. Acta Orthop Scand 41:589-607, 1970

48. Nygaard OP, Romner B, Trumpy JH: Duration of symptoms as a predictor of outcome after lumbar disc surgery. Acta Neurochir 128:53-56, 1994

49. Nystrom B: Experience of microsugical compared to conventional technique in lumbar disc operations. Acta Neurol Scand 76:129-141, 1987

50. Ozgen S, Naderi S, Ozek MM, et al: Findings and outcome of revision lumbar disc surgery. J Spinal Disord 12:287-292, 1999

51. Patel N, Pople IK, Cummins BH: Revisional lumbar microdiscectomy: an analysis of operative findings and clinical outcome. Br J Neurosurg 9:733-737, 1995

52. Ramani PS: Variations in size of the bony lumbar canal in patients with prolapse of lumbar intervertebral discs. Clin Radiol 27:301-307, 1976

53. Rogers LA: Experience with limited versus extensive disc removal in patients undergoing microsurgical operations for ruptured lumbar discs. Neurosurgery 22:82-85, 1988 
54. Sachdev VP: Microsurgical lumbar discectomy: a personal series of 300 patients with at least 1 year of follow-up. Microsurgery 7:55-62, 1986

55. Salander JM, Youkey JR, Rich NM, et al: Vascular injury related to lumbar disc surgery. J Trauma 24:628-631, 1984

56. Shaw ED, Scarborough JT, Beals RK: Bowel injury as a complication of lumbar discectomy. A case report and review of the literature. J Bone Joint Surg Am 63:478-480, 1981

57. Shvartzman L, Weingarten E, Sherry H, et al: Cost-effectiveness analysis of extended conservative therapy versus surgical intervention in the management of herniated lumbar intervertebral disc. Spine 17:176-82, 1992

58. Silvers HR: Microsurgical versus standard lumbar discectomy. Neurosurgery 22:837-841, 1988

59. Silvers HR, Lewis PJ, Asch HL, et al: Lumbar diskectomy for recurrent disk herniation. J Spinal Disord 7:408-419, 1994

60. Spangfort EV: The lumbar disc herniation. A computer-aided analysis of 2,504 operations. Acta Orthop Scand Suppl 142: $1-95,1972$

61. Spengler DM, Bigos SJ, Martin NA, et al: Back injuries in industry: a retrospective study. I. Overview and cost analysis. Spine 11:241-245, 1986

62. Striffeler H, Groger U, Reulen HJ: "Standard" microsurgical lumbar discectomy vs. "conservative" microsurgical discectomy. A preliminary study. Acta Neurochir 112:62-64, 1991

63. Thomas AM, Afshar F: The microsurgical treatment of lumbar disc protrusion. Follow-up of 60 cases. J Bone Joint Surg Br 69:696-698, 1987

64. Vucetic N, Astrand P, Guntner P, et al: Diagnosis and prognosis in lumbar disc herniation. Clin Orthop 361:116-122, 1999

65. Vucetic N, de Bri E, Svensson O: Clinical history in lumbar disc herniation. A prospective study in 160 patients. Acta Orthop Scand 68:116-120, 1997
66. Vucetic N, Svensson O: Physical signs in lumbar disc hernia. Clin Orthop 333:192-201, 1996

67. Weber H: Lumbar disc herniation. A controlled, prospective study with ten years of observation. Spine 8:131-140, 1983

68. Wiesel SW, Tsourmas N, Feffer HL, et al: A study of computer-assisted tomography. I. The incidence of positive CAT scans in an asymptomatic group of patients. Spine 9:549-551, 1984

69. Williams RW: Lumbar disc disease. Microdiscectomy. Neurosurg Clin N Am 4:101-108, 1993

70. Williams RW: Microlumbar discectomy: a conservative surgical approach to the virgin herniated lumbar disc. Spine 3: 175-182, 1978

71. Wilson DH, Harbaugh R: Microsurgical and standard removal of protruded lumbar disc: a comparative study. Neurosurgery 8:422-427, 1981

72. Wilson DH, Kenning J: Microsurgical lumbar discectomy: preliminary report of 83 consecutive cases. Neurosurgery 4: 137-140, 1979

73. Winston K, Rumbaugh C, Colucci V: The vertebral canals in lumbar disc disease. Spine 9:414-417, 1984

74. Yaşargil MG: Microsurgical operations for herniated lumbar disc. Adv Neurosurg 4:81-82, 1977 (Reference unverified)

\section{Acknowledgment}

This work was supported by a grant from the Dennis and Rose Heidl foundation.

Manuscript received June 17, 2002.

Accepted in final form July 3, 2002.

Address reprint requests to: Christopher J. Koebbe, M.D., Department of Neurological Surgery, University of Pittsburgh Medical Center, 200 Lothrop Street, Pittsburgh, Pennsylvania 15213. email: chriskoebbe@hotmail.com. 